\title{
Malassezia furfur
}

National Cancer Institute

\section{Source}

National Cancer Institute. Malassezia furfur. NCI Thesaurus. Code C127729.

A species of obligatory lipophilic, anthropophilic yeast in the phylum Basidiomycota that is part of the normal human skin flora. This species is the causative agent of pityriasis versicolor. 